\title{
Modeling Multiscale and Multiphysics Coastal Ocean Processes: A Discussion on Necessity, Status, and Advances
}

\author{
Hansong Tang ${ }^{1, *}$, Charles Reid Nichols ${ }^{2} \oplus$, Lynn Donelson Wright ${ }^{3}$ and Donald Resio ${ }^{4}$ \\ 1 Civil Engineering Department, City College of New York, CUNY, New York, NY 10031, USA \\ 2 Marine Information Resources Corporation, 340 Wye Narrows Drive, Queenstown, MD 21658, USA; \\ rnichols@mirc-us.com \\ 3 Southeastern Universities Research Association, Washington, DC 20005, USA; wright@sura.org \\ 4 Taylor Engineering Research Institute, University of North Florida, Jacksonville, FL 32224, USA; \\ don.resio@unf.edu \\ * Correspondence: htang@ccny.cuny.edu
}

Citation: Tang, H.; Nichols, C.R.; Wright, L.D.; Resio, D. Modeling Multiscale and Multiphysics Coastal Ocean Processes: A Discussion on Necessity, Status, and Advances. J. Mar. Sci. Eng. 2021, 9, 847. https:// doi.org/10.3390/jmse9080847

Academic Editor: Alvise Benetazzo

Received: 9 June 2021

Accepted: 28 July 2021

Published: 5 August 2021

Publisher's Note: MDPI stays neutral with regard to jurisdictional claims in published maps and institutional affiliations.

Copyright: (C) 2021 by the authors. Licensee MDPI, Basel, Switzerland. This article is an open access article distributed under the terms and conditions of the Creative Commons Attribution (CC BY) license (https:/ / creativecommons.org/licenses/by/ $4.0 /)$.

\begin{abstract}
Coastal ocean flows are interconnected by a complex suite of processes. Examples are inlet jets, river mouth effluents, ocean currents, surface gravity waves, internal waves, wave overtopping, and wave slamming on coastal structures. It has become necessary to simulate such oceanographic phenomena directly and simultaneously in many disciplines, including coastal engineering, environmental science, and marine science. Oceanographic processes exhibit distinct behaviors at specific temporal and spatial scales, and they are multiscale, multiphysics in nature; these processes are described by different sets of governing equations and are often modeled individually. In order to draw the attention of the scientific community and promote their simulations, a Special Issue of the Journal of Marine Science and Engineering entitled "Multiscale, Multiphysics Modelling of Coastal Ocean Processes: Paradigms and Approaches" was published. The papers collected in this issue cover physical phenomena, such as wind-driven flows, coastal flooding, turbidity currents, and modeling techniques such as model comparison, model coupling, parallel computation, and domain decomposition. This article outlines the needs for modeling of coastal ocean flows involving multiple physical processes at different scales, and it discusses the implications of the collected papers. Additionally, it reviews the current status and offers a roadmap with numerical methods, data collection, and artificial intelligence as future endeavors.
\end{abstract}

Keywords: multiscale; multiphysics; model coupling; domain decomposition; data collection; machine learning

\section{Background and Necessities}

As a consequence of environmental change and ever-expanding human activities, it has become urgently needed to investigate many emerging oceanic flow problems. Three examples manifest such needs. An anthropogenic example was the 2010 Gulf of Mexico oil spill, which started as a jet at the seafloor and rose to become floating oil patches that led to an environmental disaster [1]. Overbank compound flooding by two North Carolina coastal rivers provided an example of a complex suite of natural hazards that resulted from ocean surges, fluvial waters, and inland runoff, plus their interactions, during hurricanes Dennis and Floyd [2]. An engineering example is illustrated by the fast-growing, worldwide practice of power generation from ocean current energy, in which both local flows at turbines and the background tides play a role [3]. The study of these problems has significant impacts on advances in sciences, engineering, and resilient coastal communities. Towards the study, various programs have been established, such as Southeastern Universities Research Association (SURA), Coastal Ocean Observing and Prediction Program (SCOOP), and the NOAA Coastal and Ocean Modeling Testbed program [4]. 
The three example problems listed above have differing characteristics, but all of them bear a similar feature: they are multiscale and multiphysics in nature and present challenges to today's modeling capabilities. For instance, the BP oil spill in the Gulf of Mexico started as a fully three-dimensional (3D), high-speed jet with intense mixing, at scales on the order of $10 \mathrm{~m}$, and later it evolved into drifting patches of oil film, with scales on the order of $100 \mathrm{~km}$ horizontally. Currently, many models have been developed in the ocean science community for applications such as circulation, surges, and waves [5-8]. However, these models lack appropriate capabilities to directly account for multiscale, multiphysics phenomena, particularly those fully 3D, local, complex phenomena, such as the dynamic processes in the initial jet in the BP oil spill and water splashing as shown in Figure 1. Without a multiscale and multiphysics approach, these models could only partially simulate critical processes in those emerging problems. For instance, there is currently no single model or software package that can directly simulate the whole process from the jet all the way to the floating oil in the BP oil spill case.

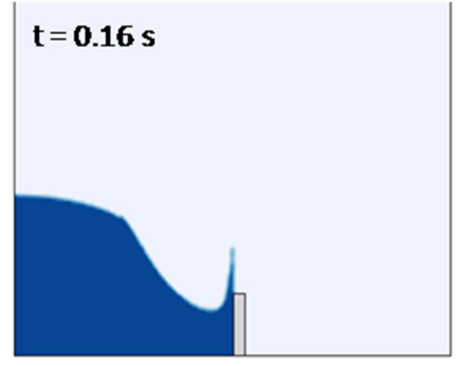

(a)

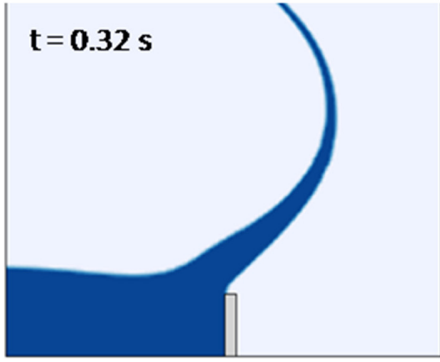

(b)

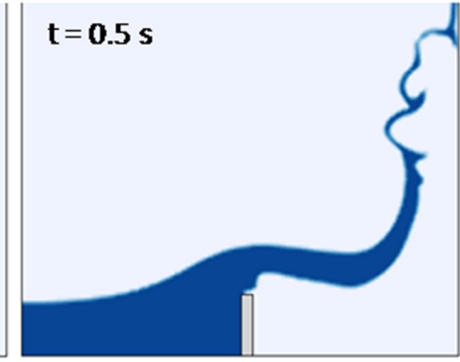

(c)

Figure 1. Simulated collapse of a water column, on the left, and its slamming on a plate, in the middle, and its splashing at a wall, on the right [9]. The simulation is produced by a solver for the Navier-Stokes equations.

For many years, oceanographers have worked towards simulating multiscale coastal ocean flows, and now it has become a common practice within the ocean science community [10-12]. For these simulations, meshes are refined locally, either via stretched meshes or nested meshes at local regions, so that not only the background large-scale flow patterns are captured, but also fine-scale, local motions are resolved. However, this is not the case for multiphysics simulations, which in general cannot be realized merely by local mesh refinement. Traditionally, multiphysics refers to a system with multiple phenomena, for instance, thermal diffusion, fluid flow, and phase change $[13,14]$. Even though these phenomena are interdependent, they are described by different governing equations. In the ocean, it is typical for a flow problem to involve multiple processes that exhibit distinct physical behaviors, e.g., a jet at the seafloor and floating oil at the water surface in the BP Deepwater Horizon Oil Spill. These processes are better described by different governing equations, and frequently they are multiscale in nature owing to a vast range of spatial and temporal scales. Therefore, they are referred to as multiphysics flows [15-17], although such terminology is not generally recognized in the ocean science community.

\section{A Discussion of the Collected Papers}

In order to promote the simulations of multiscale and multiphysics coastal ocean flows, a Special Issue of the Journal of Marine Science and Engineering entitled "Multiscale, Multiphysics Modelling of Coastal Ocean Processes: Paradigms and Approaches" was initiated [18]. This Special Issue collected several papers, each of which focused on a specific topic. Their topics included flooding, effects of scales and wind fields, model assessment, model coupling, parallel computation, and computational methods. Although small in numbers, the collected papers exemplified recent main efforts in the simulations of multi- 
scale, multiphysics flow problems. The research papers are reviewed in the paragraphs that follow.

It is common to conduct multiscale simulations by increasing mesh resolution and downscaling to resolve small-scale flow events such as flooding in the streets. When such a simulation goes into local regions, it is crucial to assure its accuracy and reliability because hydrodynamic phenomena and their interaction with the environmental settings, such as buildings, become very complicated. An indispensable step is to validate the models via abundant data that characterize the local region. Spatial complexity near the coast could be much greater than in the deep ocean where data coverage from observations and satellites requires less spatial detail. However, it is challenging to collect sufficient data during extreme coastal events, such as street-level data for swift-flowing water during storms. An innovative effort to collect street flooding data (e.g., high water marks) during two consecutive storms involved observations over a thousand local residents at Hampton Roads, VA in an activity called 'Catch the King' [19]. 'Catch the King' was well received among residents, who were educated and trained on data collection. After being processed, the data were used to calibrate the model for the VIMS' Tidewatch storm tide inundation maps. Such work is not only novel and effective to better capture local flooding but also increases the awareness of residents, bearing on a broader social impact.

In a simulation to resolve local flows, adopting appropriate models has been another critical issue besides mesh refinement along coastlines. As a result, a comparison of model performance has become necessary [20]. Driven by the need for improved marine safety and emergency response, the performance of NEMO and FVCOM was tested through scientific collaboration with multiple teams [21]. NEMO and FVCOM are two distinct types of models; the former uses a finite difference method on a structured mesh, while the latter adopts a finite volume method on an unstructured mesh. The study area is the Saint John Harbor in the Bay of Fundy, which features a complex flow system of waters from the ocean and rivers. The system exhibits intricate patterns at different scales, and its simulation is a nontrivial test for both models. The mesh resolution at the coast is as fine as about 100 $\mathrm{m}$, but the authors anticipated that both models may reach their limits if it gets further fined. The authors concluded that overall, the two models performed similarly in accuracy compared to field observation, and FVCOM has a smaller computational cost. Generally speaking, an unstructured-grid model requires more computational time, but FVCOM can deal with irregular coastlines with a smaller number of grid nodes and, which may lead to a lower computational cost. This feature has been exploited to support wave energy survey along vast portions of the coastal ocean [22].

The multiscale, multiphysics nature of coastal ocean flows is attributed to various factors, and wind fields are among those that play an essential role. With the aid of FVCOM, a comparison study was made on effects from cold fronts in 2014 and Hurricane Barry in 2019 on flow patterns inside Barataria Bay [23]. In general, these fronts and the hurricane's wind fields exhibited distinct differences not only in temporal and spatial scales but also in directions. Such differences lead to an interesting disparity in behaviors of the hydrodynamics in the bay. For instance, after the passage of a cold wind front, the water surface inside the bay presents a trough, while it exhibits surges after the hurricane. As a result, the study showed that water was transported out of the bay after a cold front of winds passes, whereas it is pushed into the bay after Hurricane Barry's landfall. This study also indicated that FVCOM was able to capture flow patterns inside a bay driven by wind fields at different scales.

Various complex flow behaviors result from the multiscale, multiphysics nature of coastal ocean flows. Extreme atmospheric wind and precipitation have contributed to unusual flooding along two rivers located along the NC coast during Hurricanes Dennis and Floyd [2]. The compound flooding events resulted from storm surges and heavy rainfall. They are each complicated phenomena but exacerbated by the simultaneous impact of the two hurricanes, resulting in interactions that contributed to dangerous flooding events. Based on data from observation and their 1D modeling, the authors 
delved into surface elevation and flow rates in the rivers, surge heights in the ocean, etc. They presented a clear description of the mechanism of the downstream blocking during the flooding. Importantly, this paper indicated that, due to strong interaction among phenomena at different scales, existing modeling approaches are not appropriate because they are typically based on univariate methods and coarse resolution. This work revealed limitations in modeling and the need for multiscale and multiphysics modeling in coastal flooding, and it concluded that approaches based on coupling of multiple models should be adopted.

Simulation of flooding events through model coupling is becoming a trend, and research related to flows along the Gulf of Mexico's continental margin represents an effort across temporal scales, where the researchers coupled models and form a holistic modeling framework to capture turbidity currents at the seabed during storms [24]. The simulation involved various physical processes, such as fluvial flows, estuary currents, surface waves, and sediment transport, which behave differently and happen at different scales. The framework assembled component models for point, 2D, and 3D processes, primarily in the one-way coupling. It simulated these processes with resolution as fine as less than $1 \mathrm{~s}$ in time and $3 \mathrm{~m}$ in space. Based on a series of simulations and analyses of their results and actual data for hurricanes Gustav and Ike, a turbidity current problem as a representation of those in the Gulf of Mexico was formulated and simulated. The simulation revealed that hurricanes could bring a substantial amount of sand from coastal to deep waters. The authors' work dealt with complex processes, and it was more complicated than earlier studies on model problems, such as the motion of sand dunes due to surface waves [25].

Due to the inherent limitations in conventional coastal ocean models' governing equations, such as the hydrostatic assumption and parameterization, they cannot handle many complex local events, especially fully small-scale, 3D phenomena. Adoption of the Navier-Stokes equations is a remedy to overcome this problem [26], since, in principle, such equations can resolve all phenomena at different scales that are of interest. However, solving these equations is very expensive, and efficient computation is a huddle for moving forward. With such motivation, a full Navier-Stokes solver on a structured mesh was developed [27]. In this solver, the Fortran-interfaced Portable-Extensible Toolkit for Scientific Computation (PETSc) library equipped with domain decomposition techniques was utilized for parallel computation of the solver, particularly its Poisson equation for pressure. Because of the adoption of such parallelization, the increased speed of computation is substantial. The work demonstrates that enough mesh resolution is desired in capturing complex flow structures at a seamount, while the resolution can be reduced in the region far away from it. This paper provided a valuable addition to the sparse number of works on domain decomposition techniques for ocean flows.

In a broader sense, domain decomposition is an indispensable approach to achieving multiscale and multiphysics simulations. A theoretical study on domain decomposition and data assimilation in the computation of a linearized version of the shallow water equations was demonstrated for Baltic Sea circulation [28,29]. In this study, assimilation data with randomness (to mimic observation data) was imposed at an open boundary of a subdomain that was linked to another subdomain. Its computation was formulated into an inverse problem, whose objective function was built on the governing equations and boundary conditions with a term of the Tikhonov regularization [28]. Additionally, a discussion on uniqueness and computational steps was presented. In a numerical experiment on a model problem, the search in the optimization converges in a few steps to the assimilation data at the open boundary. Note that simplification, such as linearization or omitting the advection terms, is made, and the scenario of this study differs from realistic situations. Nevertheless, this work is particularly valuable since its topic and methods are novel, and publications on domain decomposition for ocean flows are infrequent.

The above-collected papers provide a perspective of typical current efforts to simulate multiscale, multiphysics flow problems. However, they only reflect a portion of the past efforts. For a more complete view on the current status of such simulation, a brief but 
more comprehensive review is presented about additional work on the theme in the following section.

\section{Current Status}

Many coastal ocean models have been built on geophysical fluid dynamics (GFD) equations in the past few decades. These models have successfully simulated various applications relevant to acoustics, ocean currents, surface waves, thermoclines, etc., and examples of them are POM, ADCIRC, ROMS, WAVEWATCH [5-8]. However, they cannot handle many emerging problems involving small-scale, complicated flows, such as the examples listed at the beginning of this article, which have largely been considered as secondarily important in the ocean science communities in the past decades. At the same time, many models have been developed in the engineering communities based on different equations, e.g., the Navier-Stokes equations. In principle and practice, they can directly simulate these small-scale, complex, local ocean flows of our interest, including those in the three examples mentioned above. Figure 1 shows samples of modeling of these small-scale, complex flows. Here, "directly" means without or with minimal simplifications and parametrizations that are commonly adopted in coastal ocean models,(e.g., drag coefficients of winds over water surfaces or at the seabed). Since the computation of the equations for the local flows, e.g., the Navier-Stokes equations, is very expensive, applying these engineering models to a large area of oceans could become prohibitive. In addition, such an approach may not be as efficient as coastal ocean models, for instance, for surface waves.

For more than a decade, simulations of multiscale ocean flows have been popular among the ocean science community. Within the frame of a conventional coastal ocean model, a general approach situation is to adopt multiple grid resolutions at different zones in the domain of computation. In attempts to simulate global ocean currents, simulations obtained with different mesh resolution indicate that finer resolution is indeed helpful to better resolve observed flow patterns, such as water surface elevation and flows through straights $[30,31]$. Fine resolution is frequently applied to nearshore regions to resolve various events there. For instance, to search best sites for marine kinetic hydrodynamic energy near coastlines, grid spacing less than $10 \mathrm{~m}$ is applied along the entire coast, while that over $10 \mathrm{~m}$ is used in open waters [32]. Three sets of nested grids with 3-arcminute resolution as the fine resolution are adopted in a wave energy survey in Indonesia waters [33]. Another event with high resolution in nearshore regions is coastal flooding, and grid spacing as fine as $3 \mathrm{~m}$ is adopted to resolve floods in streets [34]. A comparison is between a structuredgrid model with nested-grids and an unstructured-grid with local mesh refinement, and it is concluded that the latter is more expensive in terms of computation [35]. It has become a common practice in the ocean science community to capture multiscale flow phenomena via local mesh refinement. Because of the complexity of the flows and their multiscale nature, it is not always straightforward to design multi-resolution meshes. For instance, a dense mesh at a tidal inlet could add dissipation to the solution there [36], and thus discretion is needed to achieve the desired accuracy there.

Multiphysics flows present more challenges, and the development of new modeling capabilities becomes necessary. Such flows tend to be associated with multiple temporal and spatial scales. However, they cannot be resolved simply by multi-resolution, or local mesh refinement, in the aforementioned conventional coastal ocean models. A direct approach is to build models on the basis of the Navier-Stokes equations or their variants in the whole computational domains [26,27]. In principle, such models, e.g., Fluidity-ICOM [26], are able to handle multiphysics flows beyond the reach of the conventional coastal ocean models, such as water slamming in Figure 1. However, like the aforementioned Navier-Stokes solvers developed in engineering communities, these models face difficulties, such as high computational cost, in application of ocean flows. Given the fact that models for individual phenomena at specific scales, e.g., large-scale ocean circulations and small-scale wave breaking, have become mature, and, as the most feasible and promising approach, it is 
natural to combine these models into a single framework to capture multiple physical phenomena, and such efforts start over a decade ago [15,37,38].

During the past decade, substantial research has focused on coupling the equations for surface waves and GFD equations (e.g., shallow water equations) for ocean currents, two typical oceanic phenomena. Examples cover the interaction between surface waves and ocean currents [39,40], wave-current-sediment motion [41], wave-driven morphology [25], effects of ocean currents on waves [42], and ice-induced wave attenuation [43]. It should be noted that waves and currents differ in temporal and spatial scales, and time steps for their computation are also distinct due to stability requirements [25,41]. Another type of coupling is between models for coastal ocean flows. Examples are coupling of a model for narrow tributaries with vertically $2 \mathrm{D}$ flow patterns to a model for 3D flows [44], a 2D Godunov-type model simulating local flooding across traffic roads to FVCOM for the background ocean currents [45], a shallow water flow solver and the Navier-Stokes solver to resolve local flows [46], and a 3D ocean model with fine grids on the order of a meter to ROMS with coarse grids [47]. As a most recent effort, solvers for the Navier-Stokes equations are coupled with FVCOM to simulate local, complex flows in high fidelity $[48,49]$. Figure 2 presents an example of this kind of coupling. In this case, the Navier-Stokes solver and FVCOM are state-of-the-art models used respectively by the engineering community and the ocean science community. Additional types of coupling include ocean circulation and sea ice [50], atmosphere, ocean, and biomaterials [51], storm surges and turbidity currents [24,46], and ocean surge and land runoff [52]. Other relevant efforts include the Earth System Modeling Framework (ESMF), which integrates many distinct geophysical models [53].

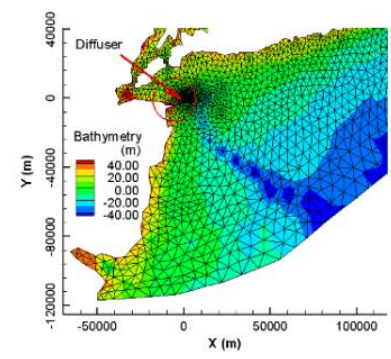

(a)

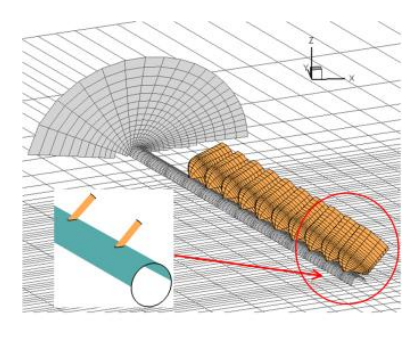

(b)

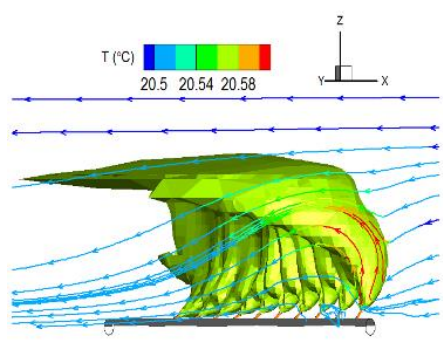

(c)

Figure 2. Simulation of thermal effluents discharged from a diffuser on seabed by coupling of a Navier-Stokes solver and FVCOM [16,48]. In the simulation, the former resolves local flows, and the latter captures the background currents, and the two models are coupled in two-way and march in time simultaneously. (a) Mesh of FVCOM. (b) Mesh of the Navier-Stokes equations solver. (c) Simulated thermal effluent at flood tide.

In general, coupling models to simulate multiphysics flows is a challenging complex task. Currently, the coupling is usually one-way, which is implemented by programs or manually, e.g., [24]. The one-way coupling may not only miss the feedback between solutions of different models but may also introduce substantial errors and uncertainties when passing solution data between models [54,55]. For instance, as in [55], a European group concluded that it is required to resolve 3D flow structures in near fields and the interaction between near and far fields to reduce such inaccuracy and uncertainty in tidal power development. As a result, efforts have been made to achieve two-way coupling, e.g., $[45,48,49,56]$. However, the bidirectional coupling is not yet widespread because it is challenging to realize and expensive to compute.

Efforts have been made on algorithm development and computational analysis to promote multiscale and multiphysics simulations. As another approach, the hybrid methods have been investigated, which merge different algorithms within a same model, rather than coupling different models as discussed above. For instance, equations for wave, current, and morphology are discretized and computed in a single system [25]. It is pro- 
posed to adopt a hybrid of continuous and discontinuous Galerkin methods to compute a generalized wave-continuity equation in ADCIRC [57]. In capturing internal waves, a method is proposed to combine a hydrostatic simulation on a grid and a non-hydrostatic simulation on another grid, plus a technique to switch between the two solutions [58]. A method that allows different time steps in different zones of the computational domain is presented to solve the shallow water equations [59]. Within ROMS, techniques are presented to realize two-way nesting to resolve local flows [60].In the past year, attempts have been made to analyze methods and computation, although such analyses are difficult and progress is limited due to the complexity of involved governing equations and also ocean flows. Research examples include optimal interface conditions to couple hydrostatic and nonhydrostatic ocean models [61], variational data assimilation [28], computational algorithms [62], and interface algorithms and stability analysis [63]. In a broad sense, all of these efforts fall into heterogeneous domain decomposition methods for coupling and computation with different partial differential equations, distinct numerical methods, and even dissimilar meshes [12].

\section{Future Efforts}

To move forward, important aspects that deserve efforts are mathematical foundation, algorithms, and computational power. In coupling different models, a crucial issue is to develop algorithms for computations at interfaces. Currently, interface treatments are ad hoc in theoretical foundations and crude in numerical methods. For instance, as a common practice, the coupling is one-way and implemented by linear interpolation $[24,46,48]$. The one-way coupling, i.e., from a far field to its near field, ignores the feedback from the other direction. While it captures physical phenomena in limited situations, the coupling may introduce substantial uncertainties and errors, e.g., during storms in which the flows are complex and highly transient. Linear interpolation is 2nd-order accurate locally, while frequently flow solvers, e.g., FVCOM, adopt second-order accurate schemes, and thus their solutions are 3rd-order accurate locally. As a result, the accuracy of the numerical solution degenerates at the interfaces. In the case of two-way coupling, the coupling issue becomes more complicated and challenging to study. Additional issues are stability, convergence, acceleration of computation, etc. In the past, only minimal efforts have been made on analysis on these issues, e.g., interface conditions, algorithms, optimal Schwarz iteration $[61,62,64]$. These issues present a great challenge to us in practical computations. Examples include numerical oscillations, delay of response in solution, and even non-physical solutions occurring at interfaces [64]. Domain decomposition is a broad framework for coupling of different models, and its research has been extensive in the mathematics community, e.g., [12,14], but with very sparse efforts for problems of interests to the ocean science community, e.g., references $[27,28]$ collected in this Special Issue. Therefore, advances of domain decomposition methods are yet to be made directly for ocean flows. Sufficient research on all of these issues with rigorous foundations and better ways is indispensable before multiscale and multiphysics simulations become widespread within the oceanography community and reach the capability levels of directly dealing with real-world problems like the example problems illustrated in Section 1.

Another indispensable aspect of future efforts is the measurement of data in laboratory experiments and field observations. Due to various uncertainties and shortages in models, measured data play a crucial role in model validation and calibration, assuring they work correctly and reliably. Besides regional data primarily associated with conventional large-scale modeling approaches, measurements that reflect multiscale and multiphysics features, particularly those for small-scale, local flows, are highly desirable. For example, in an attempt to model correlations between background ocean currents and mixing flows generated by an offshore floating windmill farm, simultaneous observations in the far fields as well as in the near fields of each floating device are needed. In some situations, e.g., storm surge impinges coastal infrastructures, special data for engineering purposes, such as those on impinging pressure on the infrastructure, are desired, e.g., in simulations 
of the impact loads. In the past, numerous measurement programs have focused on revealing large-scale phenomena and their interaction, such as ocean tides, estuarine circulation, and offshore upwelling $[65,66]$. However, there is lack of measurements for local phenomena, especially those in conjunction with those for background flows, and data archives that characterize multiscale, multiphysics features are minimal. For instance, although an intensive experimental study has been made to understand the impact of tsunamis on coastal structures in recent years, they are focused on local flows without consideration or with substantial simplification for actual real background far-field flows, e.g., [67]. As a result, mostly the newly developed models with multiscale, multiphysics capabilities, such as the modeling system used to produce the simulation in Figure 2, have not fully be validated and tested by data with multiscale, multiphysics information. Therefore, obtaining sufficient measurement data for modeling multiscale and multiphysics processes remains a key priority and requires improved instrument networks [68,69].

As a potential direction for future development, efforts on data-driven methods and artificial intelligence are expected to grow rapidly, which could lead to new avenues to simulations of multiscale and multiphysics ocean flows. Since such flows result from various factors (e.g., wind, tide, bathymetry), their interactions, and associated uncertainties (e.g., randomness of wind), it has been a challenging task to reliably to take all of them into consideration using conventional physical and deterministic approaches as discussed above. Artificial intelligence is based on datasets that contain the info of such factors, and data-driven methods could overcome the challenges. The ideas to study ocean flows via a data-driven approach started a long time ago, such as using artificial neural networks to identify ocean currents with satellite images [70], predict storm surge with data of wind, air pressure, and tidal level [71], simulate ocean-water overtopping at structures [72], estimate waves using observed and modeled data [73], track ocean drifters according to their motion histories [74]. Now, it has been recognized in the ocean science community that data-driven artificial intelligence will be a future direction [75]. In recent years, the progress in artificial intelligence is encouraging on topics of resolving complex physics and rigorous foundations; they cover reproducing flow patterns [76], solving the Navier-Stokes equations [77], constructing turbulence closures [78], and exploring the mathematical foundation of machine learning [79]. Figure 3 shows the prediction capability of machine learning for a cavity flow. In this example, 20 images of the velocity field (vertical velocity, w) at different Reynolds numbers $\operatorname{Re}=300, \ldots, 390,410, \ldots$, 500 (without that at $\operatorname{Re}=400$ ) as training data are used to train neural networks. The trainingusesthe velocity at the upper and lower parts as input and velocity in the middle zone, an interface zone, as output. It is seen that then the trained networks satisfactorily predict the velocity at $\operatorname{Re}=400$ in the interface zone. Note that, at the same time, machine learning tools have become mature, such as Tensorflow [80], Pythoch [81], and Matlab [82], and they are open-source for application to various problems. Very recently, it is proposed to couple differential equations and flows using machine learning [83,84]. For instance, it is shown in [84] that, after being trained by solutions of partial differential equations with an initial condition, neural-network-based interface algorithms work well in solving the equations with another initial value condition. This manifests that machine learning does not just repeat its training data but also exhibits a certain prediction capability. Although it has not been realized yet, all of these indicate that machine learning could lead to avenues to simulations of multiscale and multiphysics ocean flows.

In efforts towards simulations of multiscale, multiphysics coastal ocean flows to meet the emerging needs in practice, such as the example problems described in Section 1, a multidisciplinary effort is dispensable. As described above and recognized by many researchers [85,86], collaboration among different communities such as ocean science, mathematics, and engineering lead to innovation. In addition, since such simulations cover various data, models, and applications, teamwork and collaboration across institutions are essential [14,86,87]. 


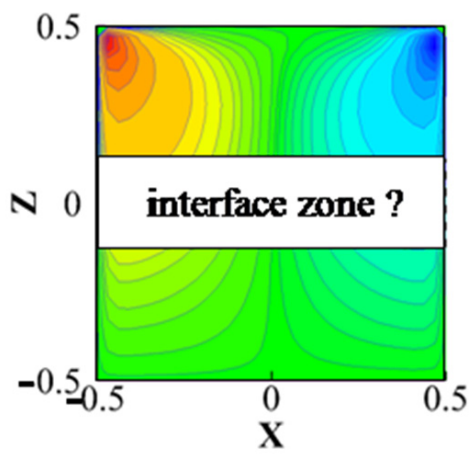

(a)

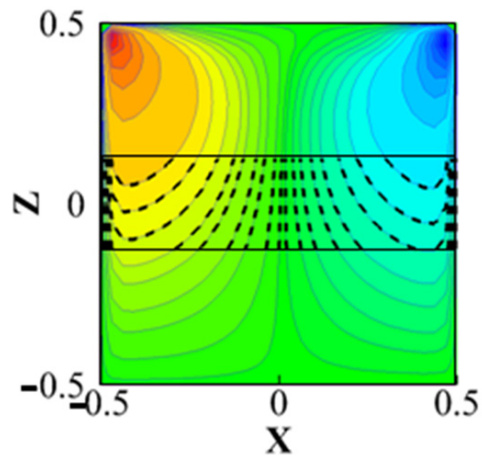

(b)

Figure 3. Example of machine learning for an unsteady, 3D cavity flow (The fluid inside a cubic box in size of $1 \times 1 \times 1$ is initially stationary and then starts to flow due to motion of the top wall at speed of $\cos (2 \pi t)) . \operatorname{Re}=400$, and $t=0.25$. Solid lines-data, dash lines-prediction. Tensorflow is used [80]. (a) Training data. (b) Data and prediction.

\section{Concluding Remarks}

Development in simulations of multiscale and multiphysics coastal ocean flows will promote research on many emerging problems resulting from changing coastal environments. This paper presents a review and discussion of such simulations, and it leads to the following conclusions:

1. Multiscale simulation has become widespread, while the multiphysics simulation remains in the preliminary stages of research

2. Model coupling is considered the most feasible and promising approach to realizing multiscale, multiphysics ocean flows for the foreseeable future, given the status of techniques and interests of funding programs.

3. Future multiscale and multiphysics research efforts will be based on rigorous foundations and methods, field data collection, and data-driven artificial intelligence.

Advances on topics such as machine learning will lead to new opportunities and breakthroughs in simulations of multiscale and multiphysics coastal oceans. Besides, the increasing needs from the communities and further development in relevant areas, e.g., computer power, will also promote the simulations. Optimistically we anticipate that understanding of multiscale and multiphysics coastal ocean phenomena will progress substantially in the coming decade.

Author Contributions: Conceptualization, H.T., C.R.N., L.D.W. and D.R.; writing-original draft preparation, H.T. and C.R.N.; writing-review and editing, H.T., C.R.N., L.D.W. and D.R. All authors have read and agreed to the published version of the manuscript.

Funding: This research received no external funding.

Institutional Review Board Statement: Not applicable.

Informed Consent Statement: Not applicable.

Data Availability Statement: No new data were created in this review article.

Acknowledgments: SURA's Coastal and Environmental Research Committee continues to promote the transdisciplinary, multi-institutional initiatives that underpin this Special Issue. The authors thank K. Qu and S. S. Li for producing some figures in this paper. They are grateful to Esme Wang and other journal editors for the help in handling and publishing the issue.

Conflicts of Interest: The authors declare no conflict of interest. 


\section{References}

1. Carriger, J.F.; Jordan, S.J.; Kurtz, J.C.; Benson, W.H. Identifying evaluation considerations for the recovery and restoration from the 2010 Gulf of Mexico oil spill: An initial appraisal of stakeholder concerns and values. Integr. Environ. Assess. Manag. 2015, 11, 502-513. [CrossRef]

2. Pietrafesa, L.J.; Zhang, H.; Bao, S.; Gayes, P.T.; Hallstrom, J.O. Coastal Flooding and Inundation and Inland Flooding due to Downstream Blocking. J. Mar. Sci. Eng. 2019, 7, 336. [CrossRef]

3. Neill, S.P.; Angeloudis, A.; Robins, P.E.; Walkington, I.; Ward, S.L.; Masters, I.; Lewis, M.J.; Piano, M.; Avdis, A.; Piggott, M.D.; et al. Tidal range energy resource and optimization-Past perspectives and future challenges. Renew. Energy 2018, 127, 763-778. [CrossRef]

4. Nichols, C.R.; Wright, L.D. The Evolution and Outcomes of a Collaborative Testbed for Predicting Coastal Threats. J. Mar. Sci. Eng. 2020, 8, 612. [CrossRef]

5. The Princeton Model. Available online: http:/ / www.ccpo.odu.edu/POMWEB/ (accessed on 27 July 2021).

6. ADCIRC. Available online: https://adcirc.org/community/ (accessed on 27 July 2021).

7. Regional Ocean Modeling System (ROMS). Available online: https:/ / www.myroms.org/ (accessed on 30 July 2021).

8. Wave Watch III. Available online: https:/ / polar.ncep.noaa.gov/waves/wavewatch/ (accessed on 15 March 2021).

9. Qu, K. Computational Study of Hydrodynamic Impact by Extreme Surge and Wave on Coastal Structure. Ph.D. Thesis, The City College of New York, New York, NY, USA, 2007.

10. Lermusiaux, P.F.J.; Schröter, J.; Danilov, S.; Iskandarani, M.; Pinardi, N.; Westerink, J.J. Multiscale modeling of coastal, shelf, and global ocean dynamics. Ocean Dyn. 2013, 63, 1341-1344. [CrossRef]

11. Haidvogel, D.B.; Curchitser, E.N.; Danilov, S.; Fox-Kemper, B. Numerical modelling in a multiscale ocean. J. Mar. Res. 2017, 75, 683-725. [CrossRef]

12. Tang, H.S.; Haynes, R.D.; Houzeaux, G. A Review of Domain Decomposition Methods for Simulation of Fluid Flows: Concepts, Algorithms, and Applications. Arch. Comput. Methods Eng. 2021, 28, 841-873. [CrossRef]

13. Kondic, L.; González, A.G.; Diez, J.A.; Fowlkes, J.D.; Rack, P. Liquid-State Dewetting of Pulsed-Laser-Heated Nanoscale Metal Films and Other Geometries. Annu. Rev. Fluid Mech. 2020, 52, 235-262. [CrossRef]

14. Keyes, D.E.; McInnes, L.C.; Woodward, C.; Gropp, W.; Myra, E.; Pernice, M.; Bell, J.; Brown, J.; Clo, A.; Connors, J.; et al. Multiphysics simulations: Challenges and opportunities. Int. J. High Perform. Comput. Appl. 2013, 27, 4-83. [CrossRef]

15. Wu, X.-G.; Tang, H.-S. Coupling of CFD model and FVCOM to predict small-scale coastal flows. J. Hydrodyn. Ser. B 2010, 22, 284-289. [CrossRef]

16. Tang, H.S.; Keen, T. Hybrid model approaches to predict multiscale and multiphysics coastal hydrodynamic and sediment transport processes. In Sediment Transport; Ginsberg, S.S., Ed.; Intech: London, UK, 2011; ISBN 978-953-307-189-3.

17. Candy, A.S. An implicit wetting and drying approach for non-hydrostatic baroclinic flows in high aspect ratio domains. Adv. Water Resour. 2017, 102, 188-205. [CrossRef]

18. Tang, H.S.; Nichols, C.R.; Resio, D.T.; Wright, D. Multiscale, Multiphysics Modelling of Coastal Ocean Processes: Paradigms and Approaches, J. Marine Science and Engineering, Special Issue. 2019. Available online: https://www.mdpi.com/journal/jmse/ special_issues/mul_model_coastal (accessed on 27 July 2021).

19. Loftis, J.D.; Mitchell, M.; Schatt, D.; Forrest, D.R.; Wang, H.V.; Mayfield, D.; Stiles, W.A. Validating an Operational Flood Forecast Model Using Citizen Science in Hampton Roads, VA, USA. J. Mar. Sci. Eng. 2019, 7, 242. [CrossRef]

20. Huang, H.; Chen, C.; Cowles, G.W.; Winant, C.D.; Beardsley, R.C.; Hedstrom, K.S.; Haidvogel, D.B. FVCOM validation experiments: Comparisons with ROMS for three idealized barotropic test problems. J. Geophys. Res. 2008, 113, c07042. [CrossRef]

21. Nudds, S.; Lu, Y.; Higginson, S.; Haigh, S.P.; Paquin, J.-P.; O’Flaherty-Sproul, M.; Taylor, S.; Blanken, H.; Marcotte, G.; Smith, G.C.; et al. Evaluation of Structured and Unstructured Models for Application in Operational Ocean Forecasting in Nearshore Waters. J. Mar. Sci. Eng. 2020, 8, 484. [CrossRef]

22. Iuppa, C.; Cavallaro, L.; Vicinanza, D.; Foti, E. Investigation of suitable sites for wave energy converters around Sicily (Italy). Ocean. Sci. 2015, 11, 543-557. [CrossRef]

23. Huang, W.; Li, C. Contrasting Hydrodynamic Responses to Atmospheric Systems with Different Scales: Impact of Cold Fronts vs. That of a Hurricane. J. Mar. Sci. Eng. 2020, 8, 979. [CrossRef]

24. Harris, C.; Syvitski, J.; Arango, H.; Meiburg, E.; Cohen, S.; Jenkins, C.; Birchler, J.; Hutton, E.; Kniskern, T.; Radhakrishnan, S.; et al. Data-Driven, Multi-Model Workflow Suggests Strong Influence from Hurricanes on the Generation of Turbidity Currents in the Gulf of Mexico. J. Mar. Sci. Eng. 2020, 8, 586. [CrossRef]

25. Wang, J.Y.; Tang, H.S.; Fang, H.W. A fully-coupled method to simulate wave, current, and morphology system. Comm. Nonlinear Sci. Numer. Simul. 2013, 18, 1694-1709. [CrossRef]

26. Oishi, Y.; Piggott, M.D.; Maeda, T.; Kramer, S.C.; Collins, G.S.; Tsushima, H.; Furumura, T.; Kramer, S. Three-dimensional tsunami propagation simulations using an unstructured mesh finite element model. J. Geophys. Res. Solid Earth 2013, 118, $2998-3018$. [CrossRef]

27. Valera, M.; Thomas, M.P.; Garcia, M.; Castillo, J.E. Parallel Implementation of a PETSc-Based Framework for the General Curvilinear Coastal Ocean Model. J. Mar. Sci. Eng. 2019, 7, 185. [CrossRef]

28. Agoshkov, V.; Lezina, N.; Sheloput, T. Domain Decomposition Method for the Variational Assimilation of the Sea Level in a Model of Open Water Areas Hydrodynamics. J. Mar. Sci. Eng. 2019, 7, 195. [CrossRef] 
29. Agoshkov, V.I.; Zalesny, V.B.; Sheloput, T.O. Variational Data Assimilation in Problems of Modeling Hydrophysical Fields in Open Water Areas. Izv. Atmos. Ocean. Phys. 2020, 56, 253-267. [CrossRef]

30. Ringler, T.; Petersen, M.; Higdon, R.L.; Jacobsen, D.; Jones, P.W.; Maltrud, M. A multi-resolution approach to global ocean modeling. Ocean Model. 2013, 69, 211-232. [CrossRef]

31. Wang, Q.; Wekerle, C.; Danilov, S.; Wang, X.; Jung, T. A $4.5 \mathrm{~km}$ resolution Arctic Ocean simulation with the global multi-resolution model FESOM 1.4. Geosci. Model Dev. 2018, 11, 1229-1255. [CrossRef]

32. Tang, H.; Kraatz, S.; Qu, K.; Chen, G.; Aboobaker, N.; Jiang, C. High-resolution survey of tidal energy towards power generation and influence of sea-level-rise: A case study at coast of New Jersey, USA. Renew. Sustain. Energy Rev. 2014, 32, 960-982. [CrossRef]

33. Ribal, A.; Babanin, A.V.; Zieger, S.; Liu, Q. A high-resolution wave energy resource assessment of Indonesia. Renew. Energy 2020, 160, 1349-1363. [CrossRef]

34. Blumberg, A.F.; Georgas, N.; Yin, L.; Herrington, T.O.; Orton, P.M. Street-Scale Modeling of Storm Surge Inundation along the New Jersey Hudson River Waterfront. J. Atmos. Ocean. Technol. 2015, 32, 1486-1497. [CrossRef]

35. Biastoch, A.; Sein, D.; Durgadoo, J.; Wang, Q.; Danilov, S. Simulating the Agulhas system in global ocean models-Nesting vs multi-resolution unstructured meshes. Ocean Model. 2018, 121, 117-131. [CrossRef]

36. Greenberg, D.A.; Dupont, F.; Lyard, F.H.; Lynch, D.R.; Werner, F.E. Resolution issues in numerical models of oceanic and coastal circulation. Cont. Shelf Res. 2007, 27, 1317-1343. [CrossRef]

37. Fringer, O.; McWilliams, J.; Street, R. A New Hybrid Model for Coastal Simulations. Oceanography 2006, 19, 64-77. [CrossRef]

38. Qia, J.; Chen, C.C.; Beardsley, R.C.; Perrie, W.; Cowles, G.W.; Lai, Z. An unstructured-grid finite-volume surface wave model (FVCOM-SWAVE): Implementation, validations and applications. Ocean. Model. 2009, 28, 153-166. [CrossRef]

39. Bennis, A.-C.; Ardhuin, F.; Dumas, F. On the coupling of wave and three-dimensional circulation models: Choice of theoretical framework, practical implementation and adiabatic tests. Ocean Model. 2011, 40, 260-272. [CrossRef]

40. Couvelard, X.; Lemarié, F.; Samson, G.; Redelsperger, J.-L.; Ardhuin, F.; Benshila, R.; Madec, G. Development of a two-waycoupled ocean-Wave model: Assessment on a global NEMO(v3.6)-WW3(v6.02) coupled configuration. Geosci. Model Dev. 2020, 13, 3067-3090. [CrossRef]

41. Warner, J.C.; Sherwood, C.R.; Signell, R.; Harris, C.; Arango, H.G. Development of a three-dimensional, regional, coupled wave, current, and sediment-transport model. Comput. Geosci. 2008, 34, 1284-1306. [CrossRef]

42. Abolfazli, E.; Liang, J.; Fan, Y.; Chen, Q.J.; Walker, N.D.; Liu, J. Surface Gravity Waves and Their Role in Ocean-Atmosphere Coupling in the Gulf of Mexico. J. Geophys. Res. Oceans 2020, 125, 014820. [CrossRef]

43. Bai, P.; Wang, J.; Chu, P.; Hawley, N.; Fujisaki-Manome, A.; Kessler, J.; Lofgren, B.M.; Beletsky, D.; Anderson, E.J.; Li, Y. Modeling the ice-attenuated waves in the Great Lakes. Ocean Dyn. 2020, 70, 991-1003. [CrossRef]

44. Chen, X. Dynamic coupling of a three-dimensional hydrodynamic model with a laterally averaged, two-dimensional hydrodynamic model. J. Geophys. Res. 2007, 112, c07022. [CrossRef]

45. Tang, H.; Kraatz, S.; Wu, X.; Cheng, W.; Qu, K.; Polly, J. Coupling of shallow water and circulation models for prediction of multiphysics coastal flows: Method, implementation, and experiment. Ocean Eng. 2013, 62, 56-67. [CrossRef]

46. Fujima, K.; Masamura, K.; Goto, C. Development of the 2D/3D Hybrid Model for Tsunami Numerical Simulation. Coast. Eng. J. 2002, 44, 373-397. [CrossRef]

47. Choboter, P.F.; Garcia, M.; De Cecchis, D.; Thomas, M.; Walter, R.K.; Castillo, J.E. Nesting nonhydrostatic GCCOM within hydrostatic ROMS for multiscale coastal ocean modeling. In Proceedings of the OCEANS 2016 MTS/IEEE Monterey, Monterey, CA, USA, 19-23 September 2016; pp. 1-4. Available online: https://ieeexplore.ieee.org/document/7761488 (accessed on 27 July 2021).

48. Tang, H.; Qu, K.; Wu, X. An overset grid method for integration of fully 3D fluid dynamics and geophysics fluid dynamics models to simulate multiphysics coastal ocean flows. J. Comput. Phys. 2014, 273, 548-571. [CrossRef]

49. Qu, K.; Tang, H.; Agrawal, A. Integration of fully 3D fluid dynamics and geophysical fluid dynamics models for multiphysics coastal ocean flows: Simulation of local complex free-surface phenomena. Ocean Model. 2019, 135, 14-30. [CrossRef]

50. Perezhogin, P.; Chernov, I.; Iakovlev, N. Advanced parallel implementation of the coupled ocean-ice model FEMAO (version 2.0) with load balancing. Geosci. Model Dev. 2021, 14, 843-857. [CrossRef]

51. Sein, D.V.; Groger, M.; Cabos, W.; Alvarez-Garcia, F.J.; Hagemann, S.; Pinto, J.G.; Izquierdo, A.; de la Vara, A.; Koldunov, N.V.; Dvornikov, A.Y.; et al. Regionally coupled atmosphere-ocean-marine biogeochemistry model ROM: 2. Studying the climate change signal in the North Atlantic and Europe. J. Adv. Modeling Earth Syst. 2020, 12, e2019MS001646.

52. Wahl, T.; Jain, S.; Bender, J.; Meyers, S.; Luther, M.E. Increasing risk of compound flooding from storm surge and rainfall for major US cities. Nat. Clim. Chang. 2015, 5, 1093-1097. [CrossRef]

53. Allard, R.; Rogers, E.; Martin, P.; Jensen, T.; Chu, P.; Campbell, T.; Dykes, J.; Smith, T.; Choi, J.; Gravois, U. The US Navy Coupled Ocean-Wave Prediction System. Oceanography 2014, 27, 92-103. [CrossRef]

54. Qi, J.; Chen, C.; Beardsley, R.C. FVCOM one-way and two-way nesting using ESMF: Development and validation. Ocean Model. 2018, 124, 94-110. [CrossRef]

55. Brown, A.J.G.; Neill, S.P.; Lewis, M.J. Tidal energy extraction in three-dimensional ocean models. Renew. Energy 2017, 114, $244-257$. [CrossRef]

56. Paulsen, B.T.; Bredmose, H.; Bingham, H.B. An efficient domain decomposition strategy for wave loads on surface piercing circular cylinders. Coast. Eng. 2014, 86, 57-76. [CrossRef] 
57. Blain, C.A.; Massey, T.C. Application of a coupled discontinuous-continuous Galerkin finite element shallow water model to coastal ocean dynamics. Ocean Model. 2005, 10, 283-315. [CrossRef]

58. Botelho, D.; Imberger, J.; Dallimore, C.; Hodges, B.R. A hydrostatic/non-hydrostatic grid-switching strategy for computing high-frequency, high wave number motions embedded in geophysical flows. Environ. Model. Softw. 2009, 24, 473-488. [CrossRef]

59. Hoang, T.-T.-P.; Leng, W.; Ju, L.; Wang, Z.; Pieper, K. Conservative explicit local time-stepping schemes for the shallow water equations. J. Comput. Phys. 2019, 382, 152-176. [CrossRef]

60. Debreu, L.; Marchesiello, P.; Penven, P.; Cambon, G. Two-way nesting in split-explicit ocean models: Algorithms, implementation and validation. Ocean Model. 2012, 49, 1-21. [CrossRef]

61. Blayo, E.; Rousseau, A. About interface conditions for coupling hydrostatic and nonhydrostatic Navier-Stokes flows. Discret. Contin. Dyn. Syst. Ser. S 2016, 9, 1565-1574. [CrossRef]

62. Tang, H.; Liu, Y. Coupling of Navier-Stokes Equations and Their Hydrostatic Versions for Ocean Flows: A Discussion on Algorithm and Implementation. In Domain Decomposition Methods in Science and Engineering XXV; DD 2018. Lecture Notes in Computational Science and Engineering; Haynes, R., MacLachlan, S., Cai, X.-C., Halpern, L., Kim, H.H., Klawonn, A., Widlund, O., Eds.; Springer: Berlin, Germany, 2020; p. 138.

63. Connors, J.M.; Dolan, R.D. Stability of two conservative, high-order fluid-fluid coupling methods. Adv. Appl. Math. Mech. 2019, $11,1287-1338$.

64. Tang, H.S.; Qu, K.; Wu, X.G.; Zhang, Z.K. Domain Decomposition for a Hybrid Fully 3D Fluid Dynamics and Geophysical Fluid Dynamics Modeling System: A Numerical Experiment on Transient Sill Flow. In Mesh free Methods for Partial Differential Equations VIII; Springer Science and Business Media: Berlin, Germany, 2016; pp. 407-414.

65. NOAA NDBC. 2021. Available online: https:/ / www.ndbc.noaa.gov / (accessed on 27 July 2021).

66. Talley, L.; Pickard, G.L.; Emery, W.J.; Swift, J.H. Descriptive Physical Oceanography: An introduction, 6th ed.; Elsevier: Boston, MA, USA, 2011.

67. Chen, X.; Hofland, B.; Altomare, C.; Suzuki, T.; Uijttewaal, W. Forces on a vertical wall on a dike crest due to over-topping flow. Coast. Eng. 2015, 95, 94-104. [CrossRef]

68. Subramanian, A.C.; Balmaseda, M.A.; Centurioni, L.; Chattopadhyay, R.; Cornuelle, B.D.; DeMott, C.; Flatau, M.; Fujii, Y.; Giglio, D.; Gille, S.T.; et al. Ocean Observations to Improve Our Understanding, Modeling, and Forecasting of Subseasonal-to-Seasonal Variability. Front. Mar. Sci. 2019, 6, 427. [CrossRef]

69. Nichols, C.R.; Raghukumar, K. Marine Environmental Characterization; Morgan \& Claypool Publishers: San Rafael, CA, USA, 2020. [CrossRef]

70. Cote, S.; Tatnall, A.R.L. Estimation of ocean surface currents from satellite imagery using a Hopfield neural network. Mar. Technol. Soc. J. 1996, 30, 4-13.

71. Lee, T.-L. Neural network prediction of a storm surge. Ocean Eng. 2006, 33, 483-494. [CrossRef]

72. Geeraerts, J.; Troch, P.; De Rouck, J.; Verhaeghe, H.; Bouma, J. Wave overtopping at coastal structures: Prediction tools and related hazard analysis. J. Clean. Prod. 2007, 15, 1514-1521. [CrossRef]

73. James, S.C.; Zhang, Y.; O’Donncha, F. A machine learning framework to forecast wave conditions. Coast. Eng. 2018, 137, 1-10. [CrossRef]

74. Aksamit, N.O.; Sapsis, T.; Haller, G. Machine-Learning Mesoscale and Submesoscale Surface Dynamics from Lagrangian Ocean Drifter Trajectories. J. Phys. Oceanogr. 2020, 50, 1179-1196. [CrossRef]

75. Fringer, O.B.; Dawson, C.N.; He, R.; Ralston, D.K.; Zhang, Y.J. The future of coastal and estuarine modeling: Findings from a workshop. Ocean Model. 2019, 143, 101458. [CrossRef]

76. Wiewel, S.; Becher, M.; Thuerey, N. Latent Space Physics: Towards Learning the Temporal Evolution of Fluid Flow. Comput. Graph. Forum 2019, 38, 71-82. [CrossRef]

77. Baymani, M.; Effati, S.; Niazmand, H.; Kerayechian, A. Artificial neural network method for solving the Navier-Stokes equations. Neural Comput. Appl. 2014, 26, 765-773. [CrossRef]

78. San, O.; Maulik, R. Extreme learning machine for reduced order modeling of turbulent geophysical flows. Phys. Rev. E 2018, 97, 042322. [CrossRef]

79. Sirignan, J.; Spiliopoulos, K. DGM: A deep learning algorithm for solving partial differential equations. J. Comput. Phys. 2018, 375, 1339-1364. [CrossRef]

80. Tensorflow, An End-to-End Open Source Machine Learning Platform. Available online: https://www.tensorflow.org/ (accessed on 27 July 2021).

81. PyTorch. From Research to Production. Available online: https://pytorch.org/ (accessed on 2 August 2021).

82. MathWorks, "MATLAB". Available online: https://www.mathworks.com/products/matlab.html (accessed on 82 July 2021).

83. Pawar, S.; Ahmed, S.E.; San, O. Interface learning in fluid dynamics: Statistical inference of closures within micro-macro-coupling models featured. Phys. Fluids 2020, 32, 091704. [CrossRef]

84. Tang, H.; Li, L.; Grossberg, M.; Liu, Y.; Jia, Y.; Li, S.; Dong, W. An exploratory study on machine learning to couple numerical solutions of partial differential equations. Commun. Nonlinear Sci. Numer. Simul. 2021, 97, 105729. [CrossRef]

85. Wright, L.D.; Nichols, C.R. (Eds.) Tomorrow's Coasts: Complex and Impermanent; Coastal Research Library; Springer: Cham, Switzerland, 2019; Volume 27. 
86. Levine, R.M.; Fogaren, K.E.; Rudzin, J.E.; Russoniello, C.J.; Soule, D.C.; Whitaker, J.M. Open data, collaborative working platforms, and interdisciplinary collaboration: Building an early career scientist community of practice to lever-age ocean observatories initiative data to address critical questions in marine science. Front. Mar. Sci. 2020, 7, 1011. [CrossRef]

87. Deng, Z.; Xie, L.; Liu, B.; Wu, K.; Zhao, D.; Yu, T. Coupling winds to ocean surface currents over the global ocean. Ocean Model. 2009, 29, 261-268. [CrossRef] 